\title{
Q\&A
}

Sara Rauchwerger

\section{Q. What Does a Global Startup Need to Know to Enter China?}

\begin{abstract}
A.
With the continuous change of business environments and a competitive global economy, companies cannot afford to ignore international markets. The dependency of nations around the world on each other's products and services has raised awareness among companies of the need for a more global outlook in their approach to business. The opportunities are abundant; however, the means to success must be carefully analyzed in the targeted markets. Exploiting market opportunities is about making the right decisions based on a sound analysis of the each environment and target market.
\end{abstract}

Today, in some industry sectors, the only means to succeed is to become a global company from the day of inception (Bailetti, 2012; timreview.ca/article/614). Many entrepreneurs, particularly in the technology sector, now have the means to instantaneously jump-start a global company. For example, the Internet, cloud services, and mobile wireless access help entrepreneurs reach global customers and partners, and receive payments in almost any currency. Moreover, the use of the Internet and mobile wireless access has spread by leaps and bounds. More than one third of the world's population is online (ITU, 2011; tinyurl.com/6cwry5s), where they can access information, products, and services.

Since most companies are geared towards growth and expansion, companies will look to find the greatest market opportunities, and many have set their sights on China as a large and relatively untapped market. Despite the global economic downturn, China is one of the fastest growing markets and accounts for almost $25 \%$ of Internet users globally (ITU, 2011; tinyurl.com/6cwry5s). China represents a wealth of opportunity; however, these opportunities bring specific challenges. When entering the Chinese market, companies must understand the nature of these challenges, adopt appropriate strategies, and take a long-term perspective on the market's potential.

Below, seven components of an internationalization strategy are presented: market research, competitive analysis, government and legal requirements, cultural habits, marketing plan, financial analysis, and risk analysis. All of these components must be considered to meet a company's objective for growth and profitability. These components are relevant when considering any market - global or domestic - however, the discussion will focus on the particular challenges of entering the Chinese market. These insights are based primarily on the author's experience helping American, Canadian, and European startups develop and implement their internationalization strategies, especially when China is the target market.

\section{Market Research}

Companies entering the Chinese market are strategically positioning themselves for a long-term competitive advantage in a global market rather than only focusing on their own domestic market. Market research is an essential component when seeking a competitive advantage in a foreign market. Many companies would like to avoid this step and justify this line of thinking by downplaying the value of market research in a rapidly changing environment. However, the effort required for market research is minimal in comparison to the cost of not planning ahead, and it can help companies anticipate and respond quickly to industry changes.

Companies must be informed and understand their global positioning in the industry to meet their objectives. It is therefore vital that information is gathered about the trends, customers, competitors, and all other forces that play a role in the industry to be able to make sound decisions and gain a competitive advantage for strategic positioning. Market research is a process that helps identify and define market opportunities and complexities through the gathering of information. It is always thought that market research is a lengthy and formal process, and it can be. However, the pace and movement of technology, reforms, and policy changes - particularly in China - is rapid and continuously changing. The gathering of information and market intelligence must be focused on a specific target. Companies can then quickly evaluate the opportunities and position themselves strategically, and they can avoid mak- 


\section{What Does a Global Startup Need to Know to Enter China?}

Sara Rauchwerger

ing mistakes. Companies that do not conduct such market research may only later learn about the opportunities that they missed.

Consider an example of how an entrepreneur can evaluate an opportunity in a specific sector of the Chinese market. The largest global market in wireless software in the consumer space today is device applications or "apps". Companies from around the world are building apps with the hopes to be the next Rovio (developer of the popular Angry Birds app; rovio.com) and selling their apps in the largest market: China. As of May 2012, China has more than 1 billion mobile subscribers and has overtaken the U.S. as the world's largest smartphone market (MobiThinkin, 2012; tinyurl.com/cqupf6r). In 2011, China had a $298 \%$ increase in application downloads and a $187 \%$ increase in revenue generated from applications (TechNode, 2012; tinyurl.com/89uwjvr). Based on the numbers, it is evident that the Chinese market has become an important entry port for application developers because of the large demand and continuous growth.

Given this top-level insight into the market, as shown in the example above, the next steps are to determine how to capture market opportunities. This might include an evaluation of the most common types of downloads relevant to a niche market, trends, and cultural preferences for applications types. For example, online and mobile games in China are a huge market. If there are characters drawn in the game, a thorough evaluation of cultural styles should be considered. If improperly drawn, facial gestures in characters can be perceived as rude rather than entertaining, and the audience can be quickly lost due to such a cultural misunderstanding. Based on market research, a strategic plan can be put in place to help the company decide whether or not to adapt and localize their existing application.

\section{Competitive Analysis}

When entering any new market, companies should identify key competitors, along with their strategies, weakness, and strengths through a competitive analysis. It is critical to draw attention to the opportunities and the threats to the company. This analysis should evaluate the company's current industry positioning relevant to its competitors.

Entering the Chinese market brings a few additional variables into the competitive analysis. There are still many Chinese companies that are state-owned enterprises, and the government's involvement in many aspects of business brings a twist to the competitive analysis. In addition, local Chinese companies with similar brands and focus may sprout overnight in different parts of the country.

Family-owned companies can spread throughout China rapidly through their own internal network known as guanxi, which translates to "trusted relationship". Entrepreneurs should understand the central role of guanxi in the daily lives of Chinese business owners; it can make or break an opportunity. The importance of guanxi, and the need for global entrepreneurs to understand it, is discussed in more detail below and in an article by Daniel Zhou (2012; timreview.ca/article/524).

In many Chinese industry sectors, foreign brands are perceived as superior in quality, and there are many examples of companies of all sizes being received in China with open arms. This perception of quality provides an advantage to a foreign company, yet from a competitive standpoint, this perception extends to other foreign companies. An entrant's competitive analysis should not only consider local companies and state-run enterprises, it must also compete against other foreign companies.

The competitive analysis should also consider legal issues, including the potential for "copycat" products and companies. Fortunately, China's previously lax attitude toward business practices has changed slowly over the years. Following its accession into the World Trade Organization in 2001, China has provided many commitments, one of which includes adherence to international rules and conventions. Now, many legal, accounting, venture capital, and technical firms, and others in the business ecosystem, have established cross-border units of operations. Their sole objective is to help companies of all sizes understand the local environment and work closely with local government and private enterprises to create uniformity in processes that protect companies.

It is therefore vital to conduct a competitive analysis that evaluates all fronts. Not only should companies learn about the competitive landscape in China, but they should also learn about competitors from other countries that are also targeting China. Moreover, companies should determine how their ecosystem can support their entrance into a foreign market. 


\section{What Does a Global Startup Need to Know to Enter China?}

Sara Rauchwerger

\section{Governmental and Legal Requirements}

When considering entry into any foreign market, companies should understand the regulatory and legal requirements for international trade. The United States and Canada tend to have more flexible regulatory policies, when compared with China or even similar territories such as Europe. In China, regulatory policies and processes are constantly changing.

The regulatory process and government policies may seem mundane and ever-changing when viewed as a process; however, in Chinese business practice, cultural values and traditions are important considerations in implementing these processes. These values are also important in the formulation of a general entry strategy. As discussed earlier, business transactions are conducted through the establishment of networks known as guanxi. A Chinese business network operates on trust and requires relationships to be established. Building a network is imperative for the long-term success of any company entering the Chinese market.

Another challenge for global entrepreneurs is the support of the Chinese government for companies that have been "home grown" in China, some of which are replicas of foreign companies. Examples include Renren (tinyurl.com $/ 4 \mathrm{~m} 55 \mathrm{~s} 2 \mathrm{u}$ ), which is similar in nature to Facebook (tinyurl.com/kkn7l), and Tencent, with its most popular division: QQ (tinyurl.com/6hfte3). As of August 2012, Renren had over 150 million users and Tencent QQ had over 700 million users - compared with 900 million Facebook users - and both of these companies have been praised by the Chinese government as local success stories.

Beyond praise, the Chinese government's policies provide support to local companies, such as Renren and Tencent, to complicate a foreign company's entry into that market. Chinese policies create a major barrier to entry for Facebook, which has been blocked in China. The Chinese government favours local companies because it can easily monitor their social media platform for any suspicious activity and instantaneously take action without having to deal with international treaties and legal regulations.

This degree of government intervention might scare away new entrants to the market, but it should not. New entrants must understand the logic and cultural difference and work together with government entities and local companies. For example, given the circum- stances, it is probably not wise to start a social networking site that targets the Chinese market to later find it blocked. Rather, entrepreneurs should look at alternatives such as partnership opportunities with local companies or value-added services. Companies that wish to enter the Chinese market should seek to understand the policies and issues related to their targeted sector through research and relationships within their ecosystem.

Entrepreneurs should also evaluate their intellectual property rights in China. In the past, piracy has been the norm, but the legal landscape in China is changing. The laws in China have changed and continue to change to ensure that they follow the conventions of international trade. However, it is better to have a defense mechanism in China than lose out on the market from day one, because disaster can ensue if companies do not adequately protect their intellectual property. Early-stage companies with great ideas and minimal funding often delay filing patent applications and then find that their market opportunity in China is quickly eroded by copycats.

Patent applications are the best defense mechanism a company has for its long-term operation, and patents should be filed in both the company's home country and in China. The Chinese government has made great efforts to bring change to a previously lax system and stop patent infringement. Today, there are more Chinese companies filing for patent than ever before. The services of an intellectual property attorney with expertise in Chinese patent filings can be a great asset to companies deciding whether or not to enter the Chinese market and file patents in China.

Finally, companies wishing to enter the Chinese market should research the processes for busines registration, import and export, taxes, foreign exchange, profit repatriation, and financial standards. Registering a business in China can be a lengthy process and startups should evaluate the different registration options with respect to the company's long-term objectives.

\section{Cultural Habits}

China's culture deeply influences its business practices. From the 1950s to the 1980s, China was a closed society, and therefore many of the older generation lack global business experience. Businesses in China are trying to play under the same rules as the global markets yet their ideology and isolationism influence their 


\section{What Does a Global Startup Need to Know to Enter China?}

Sara Rauchwerger

thinking. There are also regional differences in China, which result from divisions between provinces, historical factors, language, and differences in weather and terrain.

The Chinese business culture has been adapting to western business ethics while establishing its own unique culture. In China, everyone over the age of 40 grew up in an era where the state provided everything, and this experience applies to most of the country's business leaders. Recognizing this background and changes to the cultural climate will help entrepreneurs understand how to work with local partners and supporting organizations.

\section{Marketing Plan}

A marketing plan provides a process and an action plan for market entry. A well considered marketing plan must include an appropriate sequence of steps that can be easily executed. The marketing plan should describe the requirements necessary to adapt to the local market, including the pricing structure, promotions, and distribution medium.

The marketing plan should also consider any language barriers that a foreign company must overcome. The first mistake that many companies make, particularly when entering China, relates to the naming of their product or company. Startups get excited about their name but do not conduct enough research to learn if the selected name can be used across global boundaries. Care should be taken to make sure the name does not potentially mean something completely different, is not offensive, or lacks its enticing qualities when viewed through the lens of a different culture. Also, it is better for companies that are entering the Chinese market to use the local language and be able to write the company or product name in Chinese characters. Companies should not underestimate this aspect of the marketing plan; a brand name can make or break a company in a foreign country.

\section{Financial Analysis}

The decision to enter a new market should always be based on a sound financial analysis. The information collected through consideration of the topics discussed above (e.g., market research, competitive analysis) will impact the financial analysis. The financial plan should evaluate returns based on a minimum level of risk where the cost of pursuing market entry is within the target budget. The plan should allow flexibility for rapid responses to external changes because the Chinese economy is growing rapidly and changes occur regularly.

Currency fluctuation can also impact the financial analysis, especially if revenues will be repatriated. Many foreign companies in China have chosen to reinvest revenues back into the company due to the complications of repatriating funds.

Another important financial consideration relates to human resources. China has been known for cheap labour rates, particularly in manufacturing. However, many startups entering China today are not hiring employees for manufacturing purposes. These companies are often looking for administrative, on-the-ground support or engineers for development and value-added services. Foreign companies are often shocked to learn that the salaries for these types of employees in China can nearly match the salaries of employees in their own country. This situation is primarily due to economic growth and the low unemployment rate for college graduates in China, who are increasing in number. Furthermore, college graduates now have the opportunity to move from job to job just to get a higher salary, and this movement has created very little company loyalty. The cost of running a business with high turnover can impact the bottom line, especially if training is necessary. A company's financial analysis should include human resource requirements because it tends to be the largest expense on the income statement.

\section{Risk Analysis}

Any strategic decision comes with some risk. Important considerations when analyzing risk include the type, source, and magnitude of the risk. This information helps a company mitigate against specific risks and devise alternative actions.

Despite its potential, the Chinese market is risky because it is still emerging and future changes are difficult to anticipate, and for a foreign company, further hidden risks may exist due to a lack of experience or understanding. A well-developed strategic positioning plan can mitigate against such risks. 


\section{What Does a Global Startup Need to Know to Enter China?}

\section{Sara Rauchwerger}

\section{Conclusion}

Companies have been forced to think globally and expand their products and services across international boundaries due to the dependency of nations around the world on each other's products and services. Startup companies are no exception; entrepreneurs are trying to reach target markets that involve global opportunities. In search of these opportunities, all eyes have recently been on China and its continuous growth. In China, companies can leverage growing market opportunities in many business sectors that are growing at a faster pace than any other region of the world.

To succeed in China, companies must understand the local environment they intend to enter, leverage reliable resources, and build trusted partnerships. Completing an analysis of the seven key components of internationalization described here, and then building an appropriate strategy based on the results, will better prepare a company to succeed in the Chinese market.

\section{About the Author}

Sara Rauchwerger is the Founder and Director of the Chamber of Commerce International Consortium for Entrepreneurs (CCICE; ccice.org), an organization that connects entrepreneurs globally. She is also the Founder and Managing Director of BG Strategy (bgstrategy.com), a leading global market entry services company, specializing in helping clients enter global markets including industry-specific investment opportunities. Ms. Rauchwerger brings over 20 years of business development and business strategy experience from both private enterprises and government contracts from various telecommunications, aerospace, and information technology companies. She has helped companies extend globally and has particular expertise in the Chinese market. Ms. Rauchwerger participates regularly as a speaker presenting globally, at board meetings, investor pitches, lectures, conferences, forums, university lectures, and other events. She holds an MBA Degree in International Business from the Grenoble Graduate School of Business, France, and a BS Degree in Aeronautical Engineering from San Jose State University, California.

Citation: Rauchwerger, S. 2012. Q\&A. What Does a Globa Startup Need to Know to Enter China? Technology (cc) BY Innovation Management Review. November 2012: 41-45. 